\title{
Processability of Biobased Thermoset Resins and Flax Fibres Reinforcements Using Vacuum Assisted Resin Transfer Moulding
}

\author{
J. Schuster $^{1 *}$, Q. Govignon ${ }^{2,3}$, S. Bickerton ${ }^{2,3}$ \\ ${ }^{1}$ University of Applied Sciences Kaiserslautern, Institut für Kunststofftechnik Westpfalz, Pirmasens, Germany; ${ }^{2}$ The University of \\ Auckland, Auckland, New Zealand; ${ }^{3}$ Centre for Advanced Composite Materials, Glenn Innes, New Zealand. \\ Email: *jens.schuster@fh-kl.de
}

Received August 25 $5^{\text {th }}, 2013$; revised September 25 $5^{\text {th }}, 2013$; accepted October $2^{\text {nd }}, 2013$

Copyright (C) 2014 J. Schuster et al. This is an open access article distributed under the Creative Commons Attribution License, which permits unrestricted use, distribution, and reproduction in any medium, provided the original work is properly cited. In accordance of the Creative Commons Attribution License all Copyrights (c) 2014 are reserved for SCIRP and the owner of the intellectual property J. Schuster et al. All Copyright (C 2014 are guarded by law and by SCIRP as a guardian.

\begin{abstract}
Biocomposite panels consisting of biobased thermoset resins (EP, PU, UP, and tannin) and flax fibre reinforcements were produced using the vacuum assisted resin transfer moulding process. Panels based on a conventional chemical-based resin matrix were also produced, and investigated comparatively. Rheometric analyses were performed to evaluate the suitability of these resins for liquid composite moulding. Tensile, shear, and impactbending tests have been carried out to assess the quality and mechanical performance of manufactured laminates. The impregnation quality was assessed by means of ultrasonic-C-scanning and microscopy. It turned out that the properties of the biobased composite panels made of biobased epoxy resin and a biobased UP-resin from the company Nuplex in New Zealand were onlay slightly inferior to those produced with a conventional epoxy resin. A biobased PU-resin from the company USSC in the USA developed voids during curing. A tannin-based resin containing of formaldehyde was not processable.
\end{abstract}

\section{KEYWORDS}

Biocomposites; Rheological Properties; Mechanical Properties; Resin Transfer Moulding (RTM)

\section{Introduction}

Conventional mineral oil-based thermoset materials have been used as matrix materials for natural fibres such as flax and hemp for more than a decade. Since mineral oil should not be regarded as a renewable resource, due to the length of time required for natural creation and shrinking world reserves, attempts have been made to produce bio-based versions of unsaturated polyester (UP), epoxy, and tannin resins [1-3]. Combining these bio-based resins with natural fibres results in composite materials, made only from renewable resources, which can be called biocomposites or green composites. However, some of the so-called bio-resins have a bio-content of just $50 \%$ or lower, and very few have achieved $100 \%$ bio-content.

Since the turn of the millennium, an increasing amount

${ }^{*}$ Corresponding author. of research has been conducted on bio-composites with an emphasis on thermoplastic matrices such as starch, poly(lactic acid) (PLA), and poly(e-caprolactone) (PCL) [4-10]. However, quite a few publications exist in the field of biothermoset-based natural fibre composites [1115] which have been applied to some prototype applications in the fields of civil and transport engineering [1618].

Natural fibres such as flax, jute, sisal, hemp, and ramie, are currently being used as reinforcements in composite manufacturing. Flax fibres in particular possess a Young's modulus comparable to glass fibres $[19,20]$ and have also been investigated as reinforcement for bio-based thermoset resins [14,21-23]. The predominant methods explored in the literature to process these systems of natural fibre and bio-based thermoset resins are compression moulding and hot-pressing [12,14,21,22]. Only Dweib et 
al. used the Vacuum Assisted Resin Transfer Moulding (VARTM) to impregnate flax mats in comparison to other reinforcements with a soybean oil based resin [23].

In this study, a selection of bio-based resins was applied in a VARTM process to impregnate a unidirectional flax fibre preform. However, less than ten different biobased resins are currently available worldwide.

In general, liquid composite moulding (LCM) processes are well suited to impregnating any type of reinforcement with thermoset resins, with VARTM being a commonly applied variant, which requires low investment in moulds and processing equipment. Vacuum Assisted Resin Transfer Moulding simply means that vacuum pressure is applied to the exit vent of the moulding tool. Thus any form of LCM process in which vacuum is used at the vent would qualify as VARTM [24]. However, the acronym VARTM is mostly applied to the process of vacuum infusion. That is the process in which the composite is formed using a single-sided rigid mould to provide part geometry and a thin flexible membrane over the fibre reinforcement, with external atmospheric pressure compressing the reinforcement against the rigid mould surface.

Figure 1 describes the consumables and components of equipment required for the VARTM-process, and the different stages in the process. Initially, layers of fibrous reinforcement are laid on the mould, which has been previously coated with a release agent, to form the preform. Peel ply is placed over the preform, allowing easy separation of the consumables from the part and creating a reasonable surface finish. Distribution media are usually laid over the peel ply to enhance the speed of resin flow. Once inlet and vent tubes are positioned, the mould is closed using a vacuum bag sealed with sealant tape (a.k.a. tacky tape). With the cavity sealed, the inlet is clamped and vacuum is applied to the vents. This stage is referred to here "pre-filling". At the end of pre-filling, the inlet is opened and the resin propagates through the prefom. During the "filling stage", pressure inside the cavity depends on position and time. Within the impregnated portion of the preform the resin pressure varies from vacuum at the flow front to atmospheric pressure at the inlet. Once the preform is completely filled, either the inlet is clamped or inlet and vent port are directly connected to equilibrate resin pressure within the laminate. The "postfilling" stage involves removal of excess resin, and allows resin pressure and laminate thickness to equilibrate within the cavity. While the resin can still bleed through the vent, the fibre volume fraction increases. In addition, resin can impregnate unsaturated fibre tows or macropores $[25,26]$. Since the resin has to flow through the relatively low permeability preform, special resins for

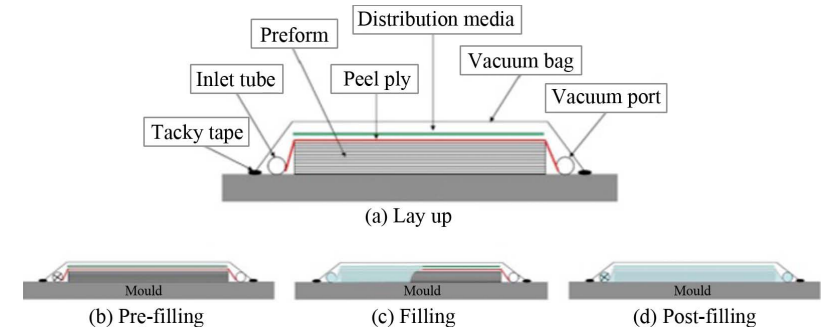

Figure 1. Schematic diagram of stages in the VARTM infusion process.

VARTM with a viscosity in a certain range have been developed. The permeability properties of flax fibre reinforcements were found to be similar to those of glass fibre preforms [27]. Therefore, the objective of this research is to evaluate the suitability of bio-based resins for resin infusion processes.

\section{Experimental}

\subsection{Materials}

\subsubsection{Resins}

Four different bio-based thermoset resins were investigated in this study, including one epoxy, one UP-resin, one PU-resin, and a tannin resin. A hot curing biobased epoxy was purchased from B.A.M Biocomposites and More GmbH in Germany, consisting of epoxidised triglycerides derived from plant oil and plant based polycarboxylic anhydride. Resin and hardener were mixed to a weight ratio of $114: 85$, and $1.5 \%$ - $5 \%$ of catalyst was added to the mixture. A cold curing PU-resin was delivered by Urethane Soy Systems Co. (USSC) in the United States, and a cold curing UP-resin was provided by Nuplex Industries in New Zealand. The USSC resin is a soybased two-component system (A and $\mathrm{B}$ ) to be mixed in a weight ratio of $88: 100$ and is $100 \%$ from renewable resources. The origin of the Nuplex resin was kept confidential by the company Nuplex and it is not known by the authors. It is a one-component $70 \%$ biobased system, which is catalysed with methyl ethyl ketone peroxide (MEKP, $1 \mathrm{wt} \%)$ and cobalt octate (0.3 wt\%). Colatan CDM GT5, the base for the tannin resin, was supplied by Christian D. Markmann GmbH in Germany. It is a natural polyphenol extracted from Quebracho Colorado (Schinopsis Lorentzii), a tree that grows in the northern area of Argentina. To prepare the resin, $44 \mathrm{wt} \%$ of GT5 is dissolved in $100 \mathrm{wt} \%$ formaldehyde solution (38\%). Tannin is a hot curing system and is mainly used for gluing of chipboards during a hot-press operation [1,2]. A standard chemical based cold curing epoxy-resin (Prime 20 from Gurit) developed for liquid composite moulding, was used as a benchmark. This system was mixed to a weight ratio of 100:26, resin to hardener. 


\subsubsection{Flax Fibre Reinforcement}

A $305 \mathrm{~g} / \mathrm{m}^{2}$ unidirectional flax reinforcement has been used due to the good mechanical properties of the flax fibres. The reinforcement was supplied by Libeco-Lagae, Belgium, and was cut into samples measuring $250 \times 400$ mm. In order to derive a final part thickness of approximately $4 \mathrm{~mm}$, 8 layers were arranged in a unidirectional lay-up. Concerns due to possible thermal degradation of flax due to exposure to high temperatures during processing of hot curing resins can be neglected, because flax is thermally stable up to a temperature of $120^{\circ} \mathrm{C}$. Above $120^{\circ} \mathrm{C}$ degradation processes will be initiated [28].

\subsection{Viscometry}

Viscosity measurements were made on all resins using a AR-G2 rheometer with a Peltier plate arrangement from TA Instruments. Each resin was subjected to a time sweep at $25^{\circ} \mathrm{C}$ for 1 hour, and a temperature sweep between $20^{\circ} \mathrm{C}$ and $120^{\circ} \mathrm{C}$ with a heating rate of $5 \mathrm{~K} / \mathrm{min}$. The resins were subjected to a frequency of $1 \mathrm{~Hz}$ and at strain of $15 \%$ without normal load.

\subsection{Differential Scanning Calorimetry}

Differential Scanning Calorimetry (DSC) analyses were performed to determine if the resins studied cured completely after being subjected to the recommended temperature-time cycle. Using a DSC-Q-1000 calorimeter from TA Instruments, the cold curing resins were processed at a $65^{\circ} \mathrm{C}$ post-curing temperature, and the hot curing systems at $120^{\circ} \mathrm{C}$. The duration of all analyses was three hours.

\subsection{VARTM-Processing}

After drying for $4 \mathrm{~h}$ at $120^{\circ} \mathrm{C}$, the flax fibre reinforcements were arranged with a $\left[0^{\circ}\right]_{8}$ stacking sequence. The fibre reinforcements have not been subjected to a particular surface treatment, because bonding agents have a different impact on mechanical properties of the composite according to the resin type used. The entire lay-up was assembled in accordance to Figure 1. Before infusion, the mixed resin was degassed in a pressure pot under vacuum for $10 \mathrm{~min}$ to reduce the air content in the resin. The maximum vacuum level was reached after a slow gradual decrease of pressure to avoid boiling of the resin. After degassing, ambient pressure was applied, forcing the resin to move into the still clamped inlet tube. Upon unclamping of the inlet, the resin flowed through the distribution media and impregnated transversely the flax preform. The last five centimetres of the preform were not covered with the distribution media, to prevent resin exiting at the vent before complete saturation of the preform, which may lead to macro void entrapment. Once the flow front had reached the end of preform, the postfilling stage was initiated, pressure at the inlet and vent being set to 500 mbar. Laminate thickness and resin pressure gradients gradually dissipate, and the pressure boundary conditions are maintained until the resin was cured. Subsequently, the cold curing resins were post-cured for seven hours at $65^{\circ} \mathrm{C}$. The infusion of the hot curing resins took place in an oven (Figure 2), at room temperature. The hot curing cycle of one hour heating up to $120^{\circ} \mathrm{C}$, a one hour hold at $120^{\circ} \mathrm{C}$, and one hour cool down was started simultaneously with the post-filling stage. Four samples with best achievable quality were produced with each resin except the tannin system.

\subsection{Ultrasonic Testing}

Ultrasonic testing was completed with a four axes immersion tank system HFUS 4200 from the Fa. Hillger in Germany. C-scans with a testing frequency of $5 \mathrm{MHz}$ (transducer V310-SU from Panametrics) and a step width of $0.5 \mathrm{~mm}$ were conducted of exemplary sections of the panels with a size of 80 by $180 \mathrm{~mm}$. The backsurface echoes were evaluated in gate with a length of $0.5 \mathrm{~ms}$ set around these echoes. All samples were scanned with the same system amplification of $55 \mathrm{~dB}$. It was not possible to inspect the Tannin-sample due to its three-dimensional distorted surface topography.

\subsection{Mechanical Properties Measurement}

\subsubsection{Tensile Tests}

Specimens with a length of $250 \mathrm{~mm}$ and a width of 25 $\mathrm{mm}$ were cut out of the cured panels in $0^{\circ}$ - and $90^{\circ}$-direction. The tensile strength, stiffness, and elongationproperties were measured according to EN ISO 527, using a tensile testing machine from Instron (model 5500R 1186). The cross-head-speed was $1 \mathrm{~mm} / \mathrm{min}$ until an elon gation of $0.3 \%$ and $5 \mathrm{~mm} / \mathrm{min}$ until failure.

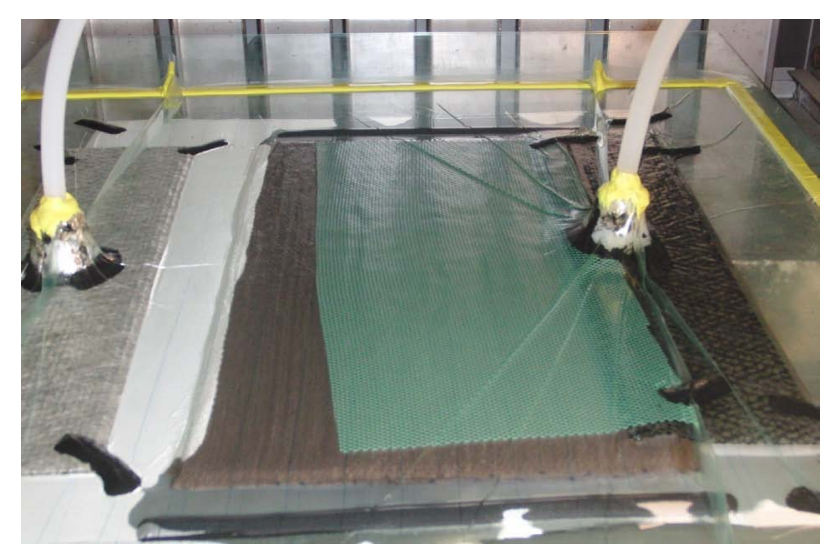

Figure 2. VARTM processing of the BAM epoxy resin within the oven. 


\subsubsection{Shear Tests}

Shear tests were performed with a custom builtlateral working shear testing device situated in a universal testing machine (Zwick 1445) as shown in Figure 3. It was constructed according to a device suggested by Lauke for curved specimens [29]. Five specimens of each fibre direction with a size of $10 \times 10 \mathrm{~mm}$ were sheared in the middle plane, with a cross-head-speed of $5 \mathrm{~mm} / \mathrm{min}$. The ultimate shear strength is computed by dividing the maximum measured shear force by the sheared area of the sample (approximately $10 \times 10 \mathrm{~mm}^{2}$ ).

\subsubsection{Impact Bending Tests}

The determination of Charpy impact strength (impact bending) was carried out according to EN ISO 179. Specimens with a length of $80 \mathrm{~mm}$ and a width of $10 \mathrm{~mm}$ were tested in an instrumented Hesscon impact tester with an impact energy of $1 \mathrm{~J}$ for the Nuplex sample and 4 $\mathrm{J}$ for the B.A.M., USSC, and Prime 20 resins. The striking area was placed perpendicular to the fibres. The tannin sample could not be tested because the necessary impact energy was below the minimum limit of the impact tester.

\subsection{Microscopy and Image Processing}

The microscopy analyses were performed with a magnification of 15 times using an optical microscope. The void contents were measured with the Vision XXL image processing system.

\section{Results and Discussion}

\subsection{Rheological Characterization}

The measured viscosity data is summarised in Table 1. It can be seen that all resins have an initial mix viscosity in the range up to 1 Pa.s. Since viscosities above 1.5 Pa.s are regarded to not be suitable for liquid composite moulding, it is clear that all of the resins studied are applicable to LCM-processes. In addition, it turned out that only the USSC PU-resin viscosity of 2.59 Pa.s exceeds this threshold within the duration of infusion (max. 20 min), which led to a very slow flow front propagation during panel manufacture.

\subsection{VARTM-Processing}

Careful observations were made during resin infusion considering two main factors; does the resin boil during degassing or curing, and will the infusion process compare well to infusion using the benchmark synthetic resin? In contrast to the other bio-based resins, the degassing of the Nuplex UP-resin proceeded without boiling. The other three resins boiled even under careful treatment, leading to overflow out of the mixing cup inside the pressure pot. Subsequently, all panel infusions proceeded without problems. Due to boiling during degassing, the tannin resin experienced a significant increase in viscosity, which resulted in a slower flow front progression than was expected. However, a complete infusion was possible. According to their relatively high viscosities, the infusions with both UP-resins were significantly slower than those with both epoxy resins (Table 2). As observed from therheometry studies, the viscosities of the PU- and the UP-resin increased very soon after mixing due to a rapid start to the curing process. This slowed down the flow front speed even more. The propagation of the USSC PU-resin was almost brought to a complete stop. Due to their low viscosities, the infusion with the epoxy resins took place within three and four minutes (Table 2). Since the hot curing B.A.M. epoxy does not cure at ambient temperature, the handling of this resin was very convenient and not time critical.

The post-filling and post-curing of the Nuplex UPresin and the hot curing B.A.M. epoxy resin proceeded

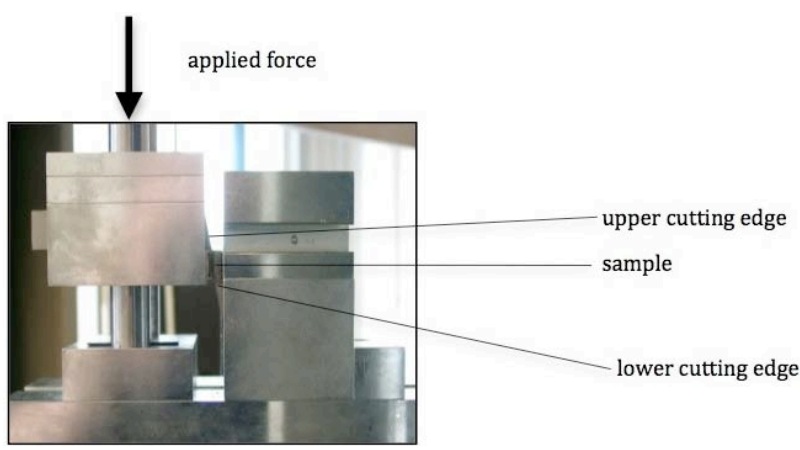

Figure 3. Experimental setup of shear testing device.

Table 1. Measured viscosities of the studied resin systems.

\begin{tabular}{cccc}
\hline Resins & Viscosity h at $20^{\circ} \mathrm{C}$ after $0 \mathrm{~s}$ in [Pa.s] & Viscosity h at $25^{\circ} \mathrm{C}$ after $0 \mathrm{~s}$ in [Pa.s] & Viscosity h at $25^{\circ} \mathrm{C}$ after $1200 \mathrm{~s} \mathrm{in}[$ Pa.s $]$ \\
\hline B.A.M. epoxy & 0.43 & 0.41 & 0.57 \\
USSC resin & 1.00 & 0.70 & 2.59 \\
Nuplex UP-resin & 0.91 & 0.65 & 1.06 \\
Tannin & 0.056 & 0.047 & 0.030 \\
Prime 20 & 0.50 & 0.39 & 0.60 \\
\hline
\end{tabular}

Table 2. Measured filling times during manufacture by VARTM.

\begin{tabular}{cccccc}
\hline Resins & B.A.M epoxy & USSC PU-resin & Nuplex UP-resin & Tannin & Prime 20 \\
\hline Filling time $[\mathrm{min}]$ & 4 & 21 & 10 & 12 \\
\hline
\end{tabular}


without problems. The USSC-PU-resin started boiling during the post-filling phase under a pressure of 500 mbar. Exploratory experiments showed that this resin also boils at ambient pressure, which leads to the conclusion that the gas bubbles are produced as a side product of the curing process. The tannin resin infused preform distorted during curing at $120^{\circ} \mathrm{C}$ in the oven and cracked the vacuum bag. During resin cure, a harmful gas, causing immediate eye burn, was created. Keeping in mind that the intention of a green composite should not be harmful in any regard, further tannin infusions were not undertaken. Fortunately, it was possible to cut samples for mechanical testing from relatively flat sections of the distorted panel.

\subsection{Ultrasonic Testing}

In general, a good impregnation results in a low sound attenuation and thus higher backsurface amplitudes. In Figure 4, high amplitudes are represented by a white or light grey colour, whereas low amplitudes are shown as dark colours. The ultrasonic-C-scans showed almost equal amplitudes for the Nuplex resin, indicating good and homogeneous fibre impregnation. The C-scans of the B.A.M. resin and Prime 20 resin possess zones with a lower sound attenuation compared with the Nuplex resin, indicating an inferior impregnation quality. It was not

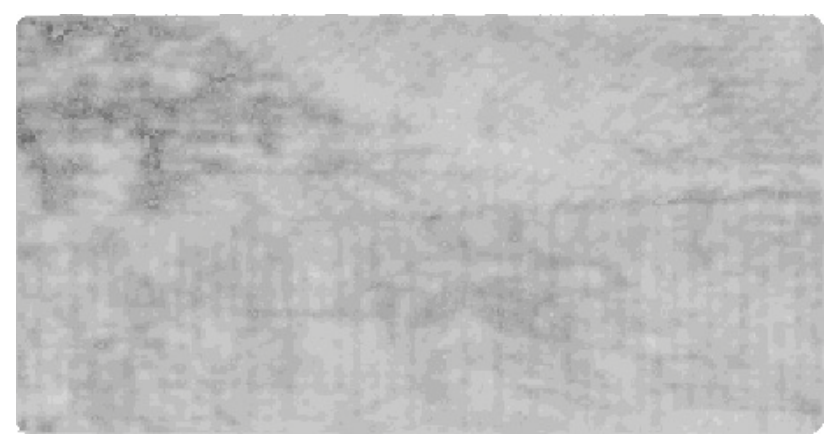

(a)

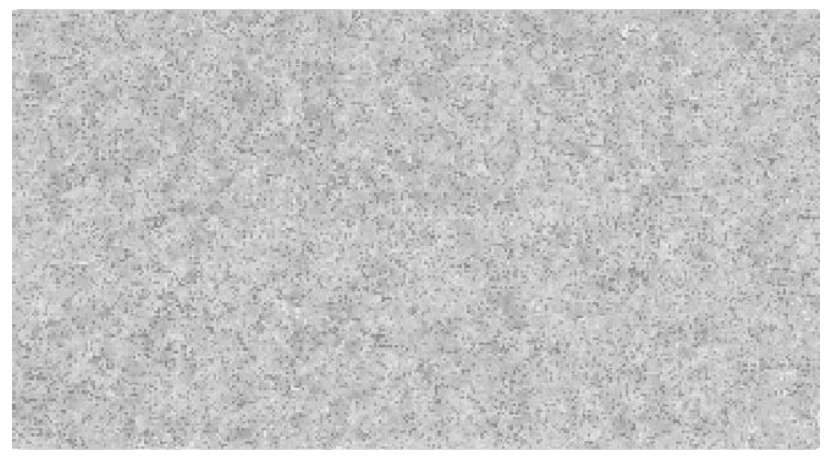

(c) possible to monitor the backsurface echo of the USSCsample due to a very high sound absorption caused by high void content.

\subsection{Mechanical Properties Measurements}

\subsubsection{Tensile Tests}

The measurement of the Young's moduli in fibre direction $\left(0^{\circ}\right)$ revealed an equal stiffness of the hot curing B.A.M. epoxy and the benchmark epoxy system as shown in Figure 5(a). Furthermore, the Young's modulus of the Nuplex UP-resin appeared to be higher than the value of the USSC PU-resin. As expected from the very flexible appearance of the tannin samples, the stiffness was significantly lower than for the other resins. Very similar trends were derived transverse to the fibre direction (Figure 5(b)) with slightly higher values of the conventional Prime 20 resin. It is clear that the stiffness properties of the epoxy resins are superior to those of the PU- and the UP-resins.

The $0^{\circ}$-tensile strength data showed no significant difresins, with the lowest values for the hot curing system (Figure 6(a)), which is due to its more brittle behaviour (Figure 7(a)). According to the stiffness measurements, the tannin had very low tensile modulus along with a high elongation. In addition, the failure mode of tannin was quite different to those of the other systems. The

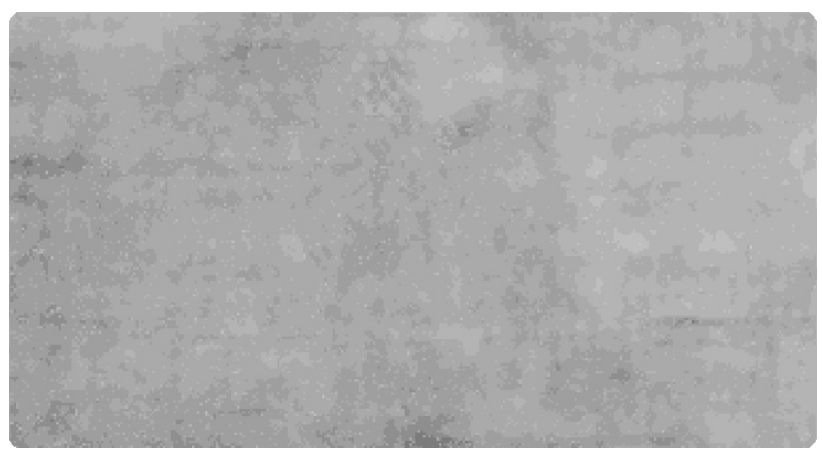

(b)

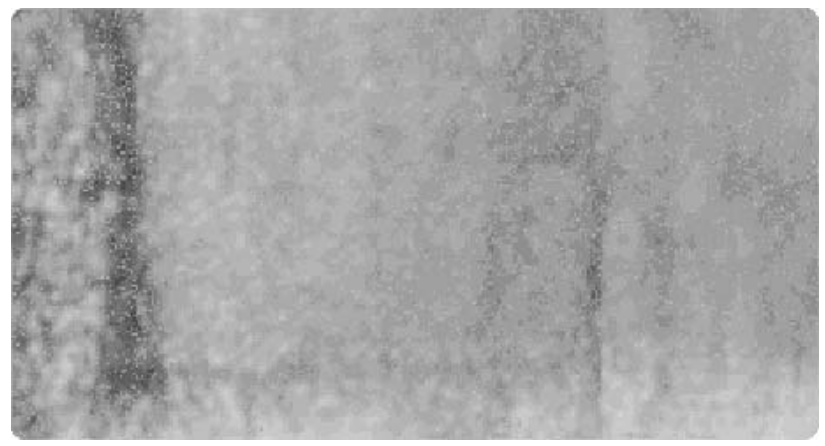

(d)

Figure 4. C-scans of panels manufactured with (a) B.A.M bio epoxy; (b) Nuplex bio UP; (c) USSC bio PU; (d) Prime 20. 


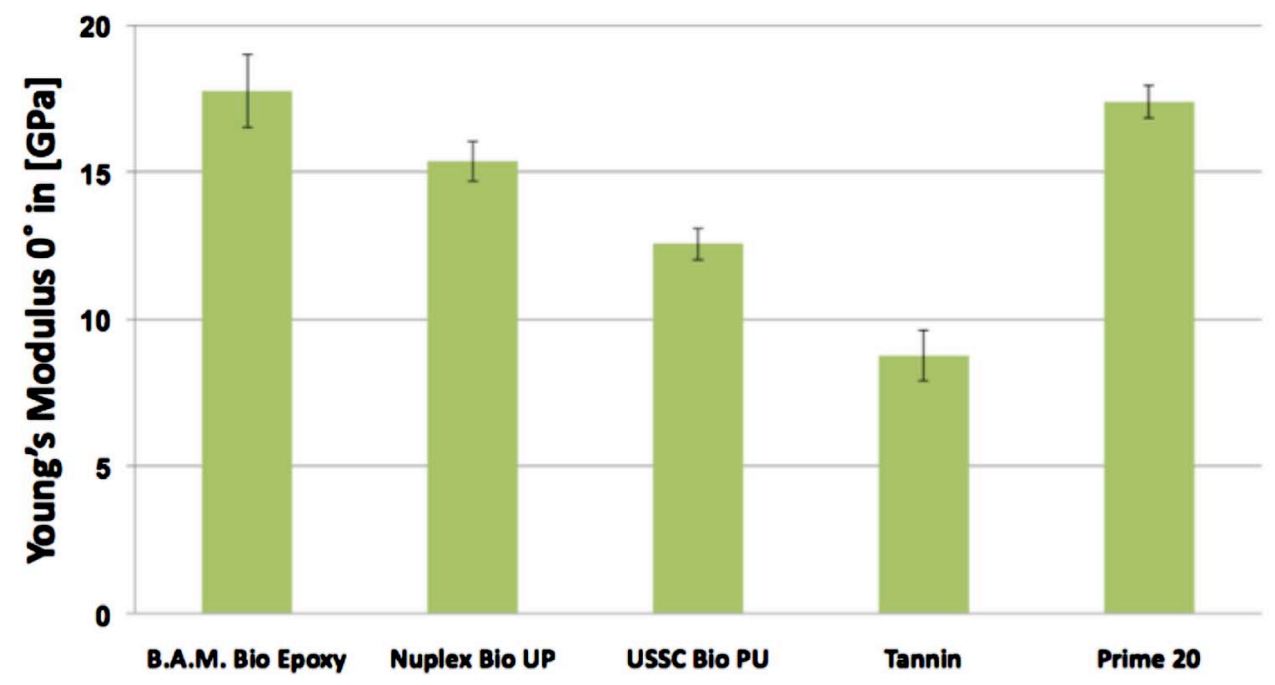

(a)

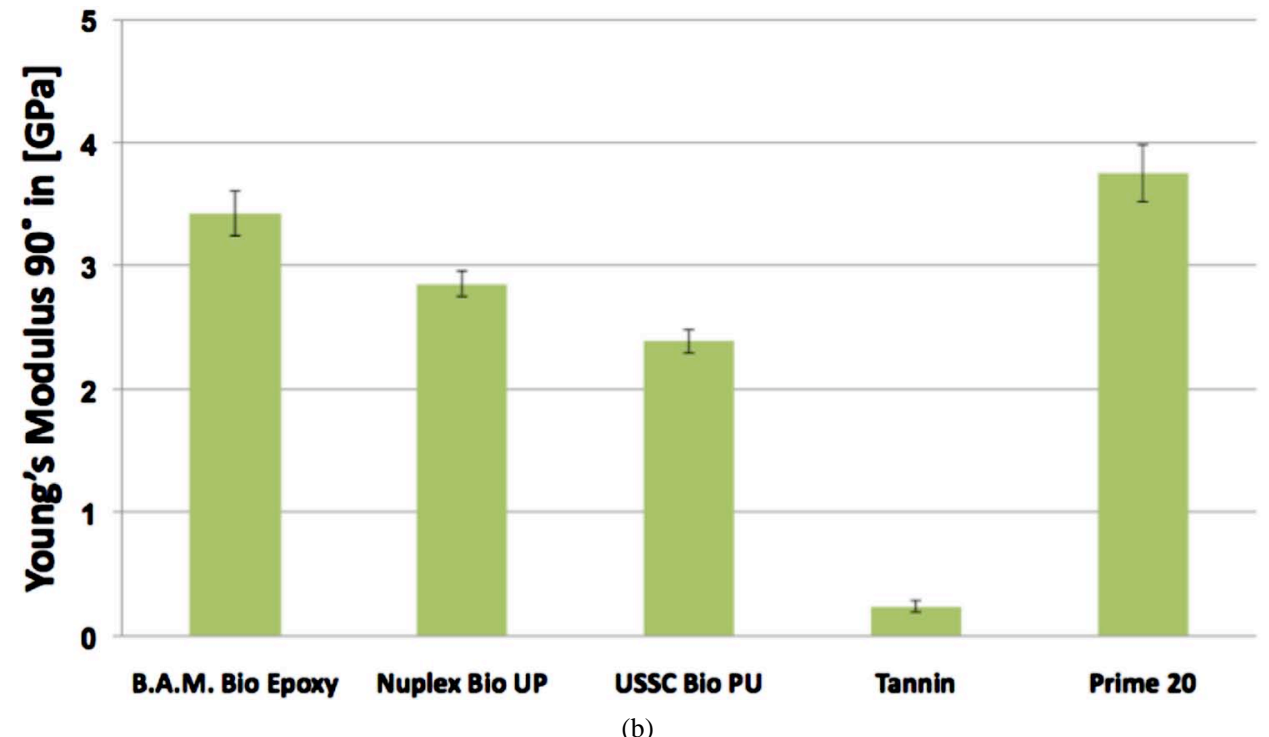

Figure 5. Measured Young's modulus, (a) In fibre direction; (b) Perpendicular to fibre direction.

epoxy and UP-resins failed due to initial longitudinal cracks in the fibre direction, leading to transverse cracks. The tannin sample delaminated between the single plies proving a weak interfacial bonding. This is also confirmed by the transverse tensile tests depicted in Figure 6(b) and the transverse ultimate elongation results in Figure 7(b). The Prime 20 epoxy possesses superior interfacial properties in comparison to the other resins. As demonstrated by the data on elongation (Figure 7), the B.A.M. epoxy is more brittle than the other epoxy and the UP-resins.

\subsubsection{Shear Tests}

The measured shear strength, as an indicator for the interfacial shear strength, is twice as high for the Nuplex UP resin than for the other resins. It was not possible to measure values for the Tannin samples (Figure 8).

\subsubsection{Impact Bending Tests}

The impact bending tests show a high impact strength for the Nuplex resin, and lower impact resistance for the other three tested resins, as depicted in Figure $\mathbf{9}$.

\subsection{Microscopy}

Evaluations of cross-sections lead to void contents of material under inspection (Table 3). It can be seen in accordance with Figure 10, that the Nuplex resin and the B.A.M. epoxy resin have the lowest void contents in comparison to other resins. The standard epoxy resin Prime 20 contained more voids than expected.

\subsection{Discussion}

The hot curing B.A.M. bio-epoxy resin and the cold 


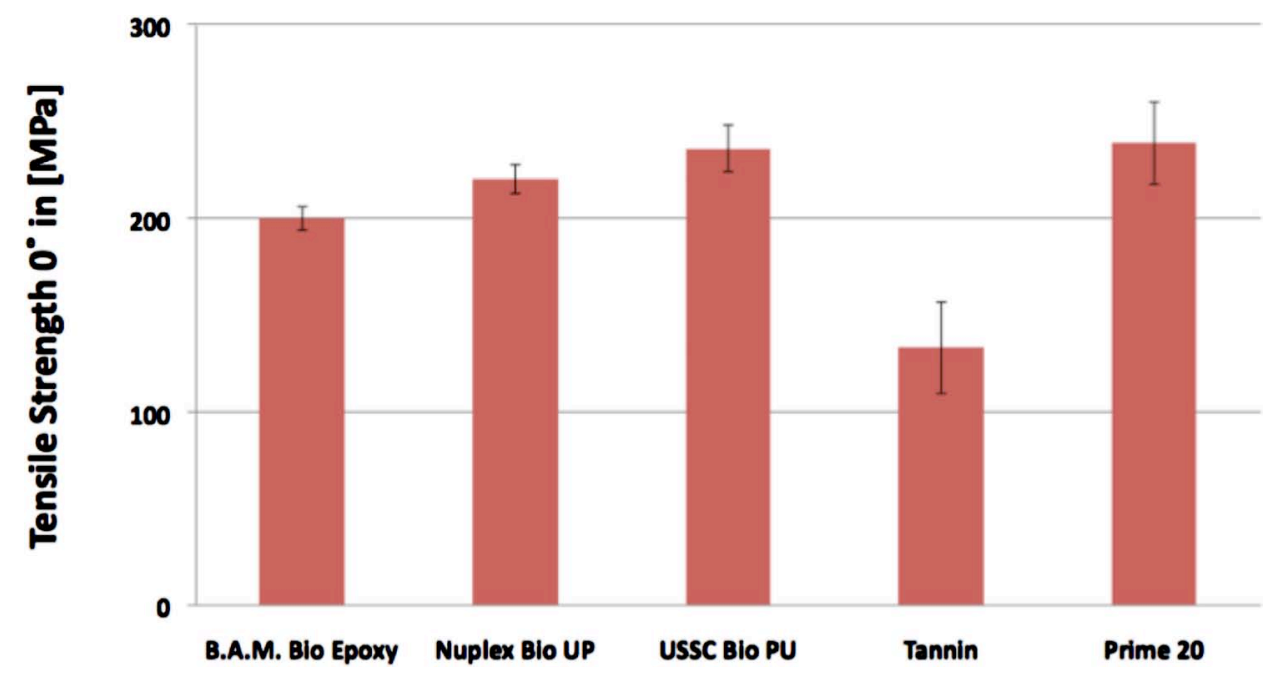

(a)

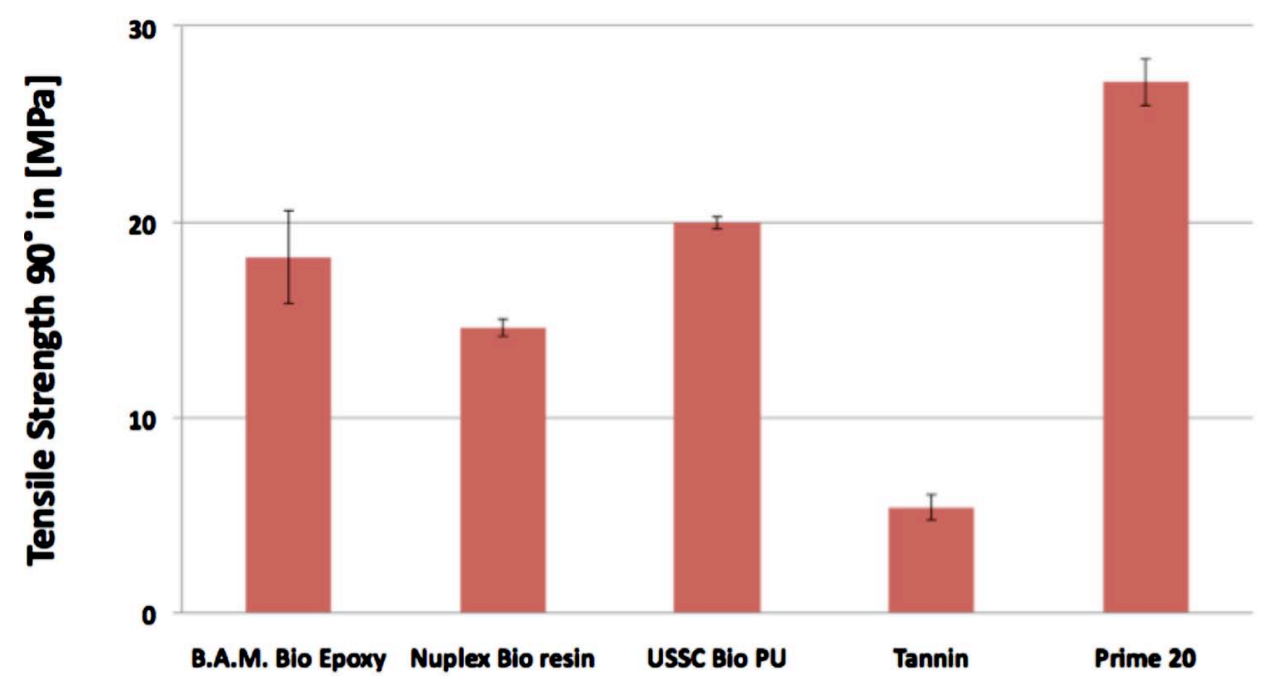

(b)

Figure 6. Measured tensile strength, (a) In fibre direction; (b) Perpendicular to fibre direction.

curing bio-resins are processable using the VARTM-process due to their viscosities being in an appropriate range. The tannin resin cannot be used for VARTM because it needs a solid die to avoid distortion of the infused part during curing. Therefore, it will not be regarded further. The USSC PU-resin is not suitable for the infusion of larger parts because the viscosity increases from an already high level of 1 Pa.s (at $25^{\circ} \mathrm{C}$ ) within 20 min to 2.59 Pa.s. In addition, the boiling of the resin during the post-filling phase resulted in an estimated void content of more than $16 \%$. Even with tensile and impact properties in the range of the other resins, the shear strength and the Young's Modulus are lower due to void induced softening.

The composite panels produced with the B.A.M. resin and the Nuplex UP resin contained only a few voids $(2 \%$ - 3.5\%), and had good mechanical properties in the range of those produced with mineral oil based benchmark resin
Prime 20. The epoxy resins are stiffer than the UP resin, while the UP resin proved superior in terms of shear strength and impact properties.

\section{Conclusions and Perspectives}

\subsection{Conclusions}

The processability and mechanical property comparison of four bio-based thermoset resins with a conventional mineral oil based resin has led to the conclusion that two bio-based resins (the B.A.M. epoxy and Nuplex UP resins) can potentially be used as a substitute for the benchmark resin. These bio-based resins have been used successfully to impregnate natural fibres using the VARTM process, without the need for further chemically based improvements such as dilutants to reduce the viscosity. Such dilutants would have had negative impact on the 


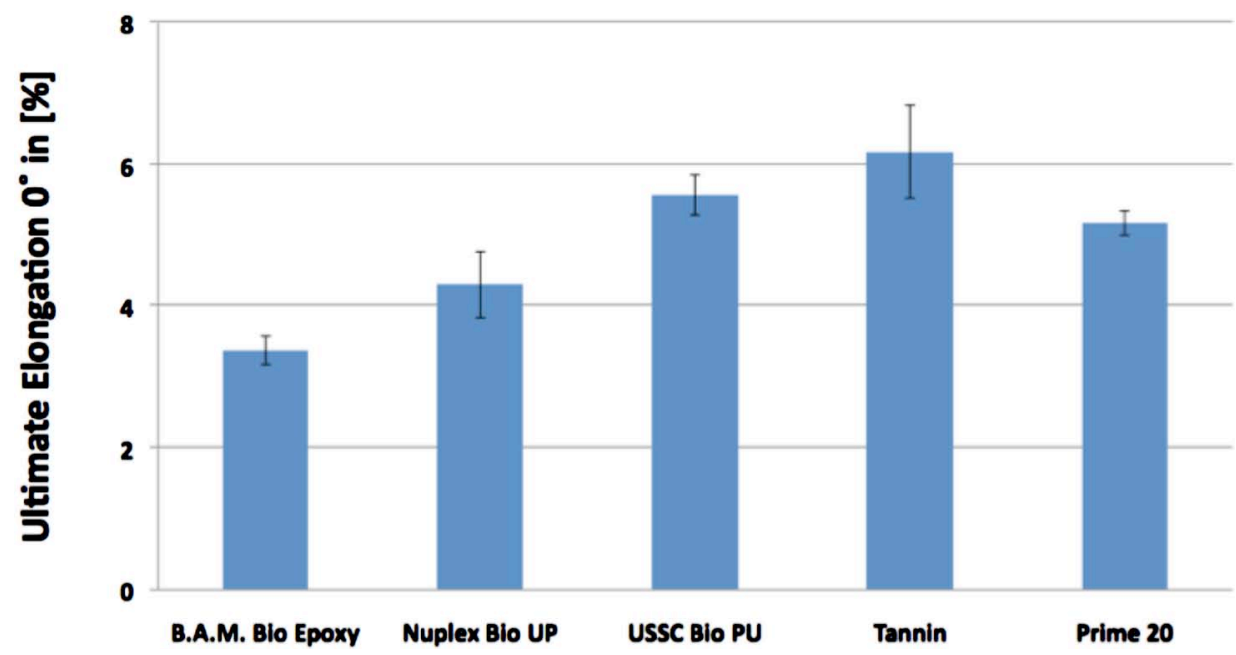

(a)

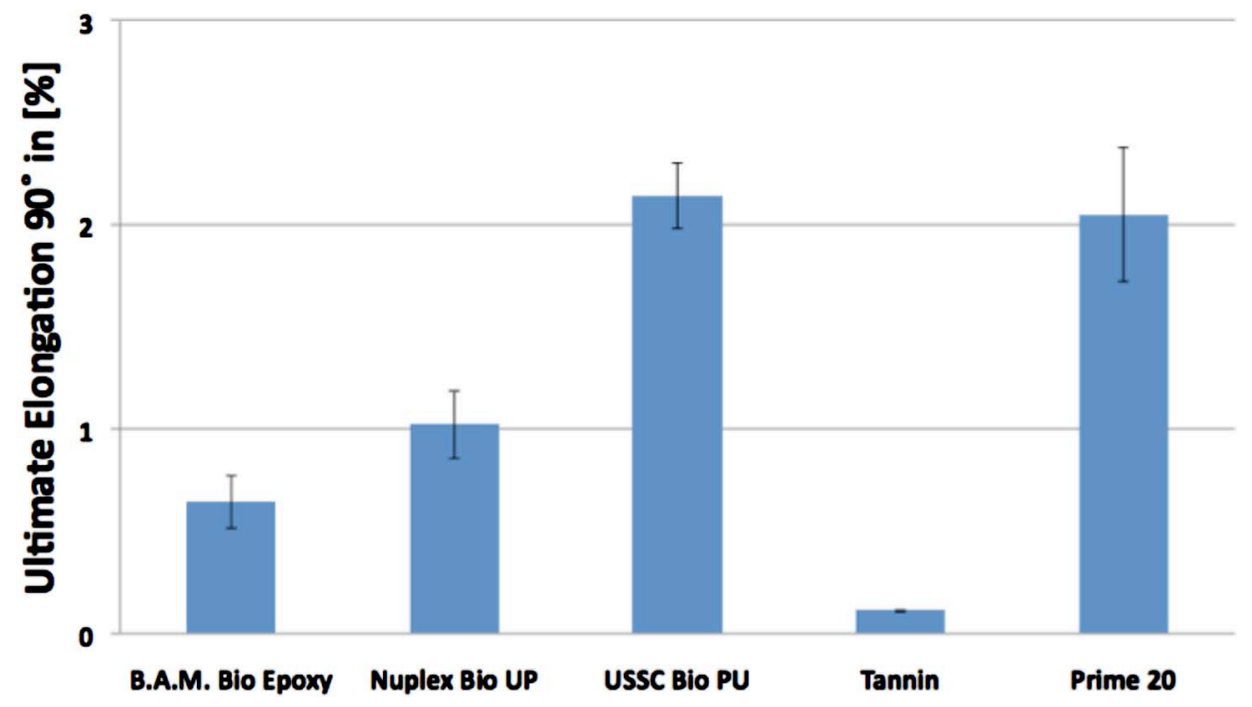

(b)

Figure 7. Measured ultimate elongation, (a) In fibre direction; (b) Perpendicular to fibre direction.

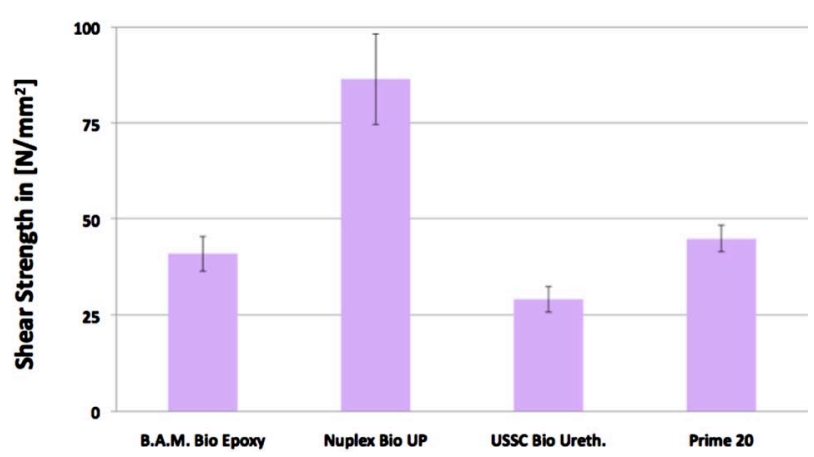

Figure 8. Measured shear strength.

biocontent. Application of the USSC PU-resin to VARTM does not seem to be reasonable, due to a high void content caused by resin boiling during the post-filling phase, and a relatively high viscosity. This boiling could not be

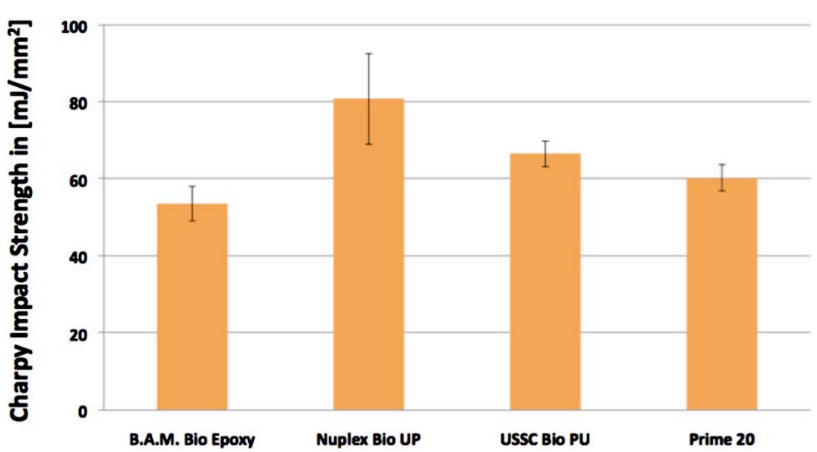

Figure 9. Measured charpy impact strength.

avoided by any means. Tannin cannot be used with a VARTM process because the infused preform distorts during curing. In addition, the high content of formaldehyde of tannin resin makes the material hazardous to 
and Flax Fibres Reinforcements Using Vacuum Assisted Resin Transfer Moulding

Table 3. Measured fibre volume fraction and void content.

\begin{tabular}{cccccc}
\hline Resins & B.A.M epoxy & USSC PU-resin & Nuplex UP-resin & Tannin & Prime 20 \\
\hline Fibre volume fraction [\%] & 38.9 & 32.1 & 41.1 & 56.3 & 40.8 \\
Void Content [\%] & 1.8 & 16.3 & 3.4 & 10.0 & 4.1 \\
\hline
\end{tabular}

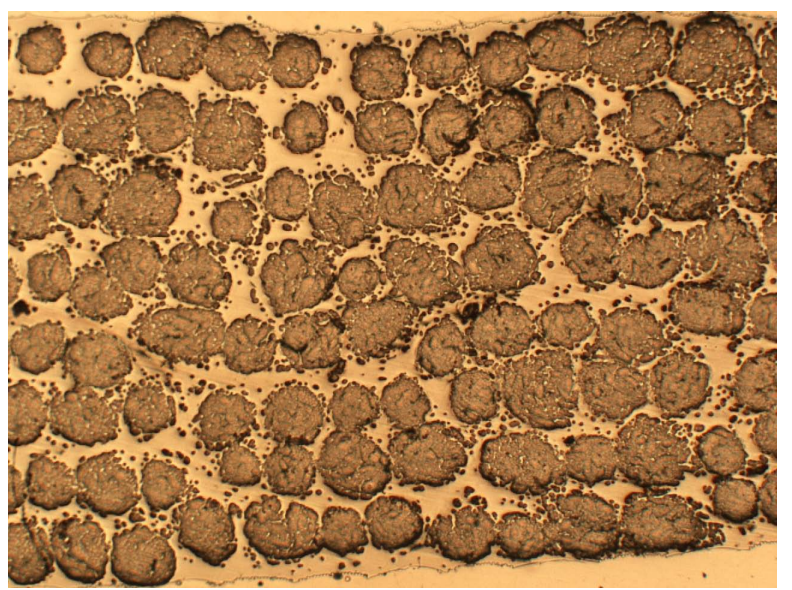

(a)

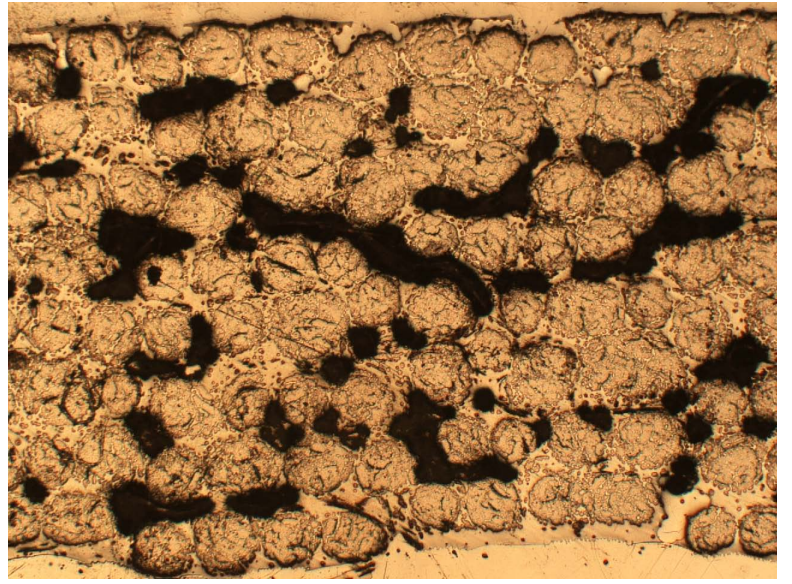

(c)

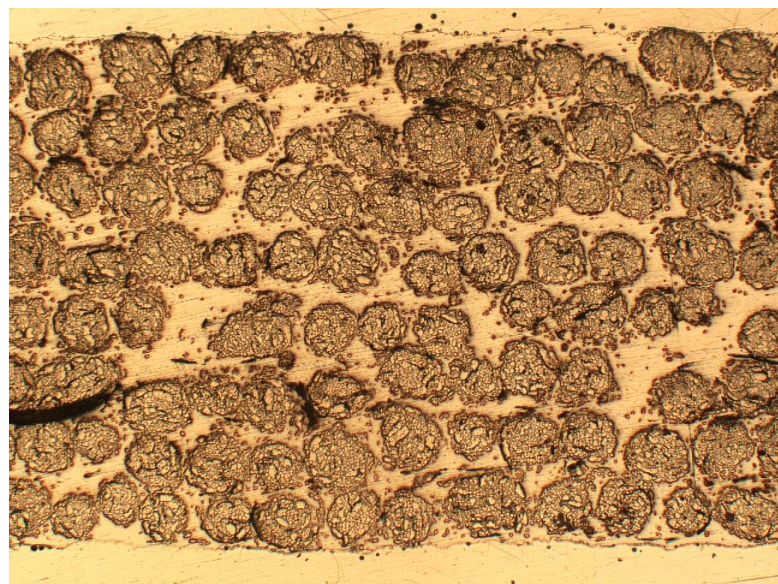

(b)

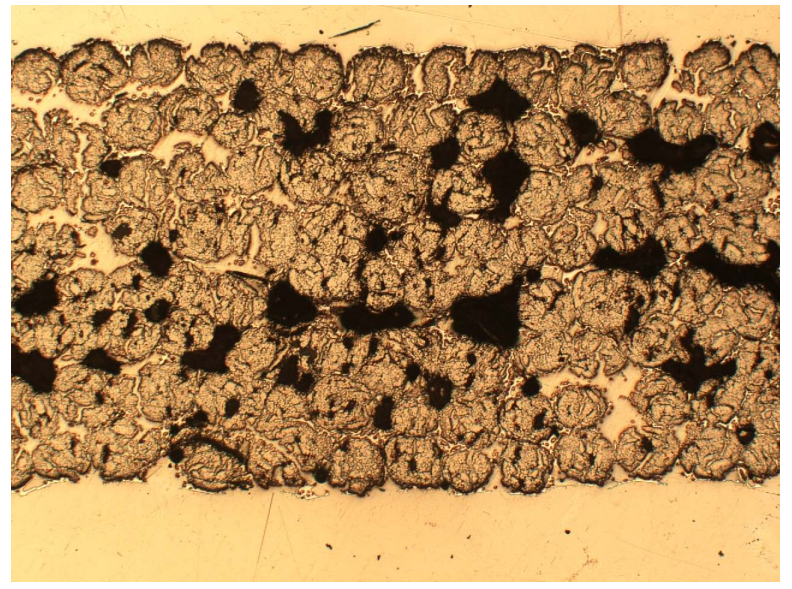

(d)

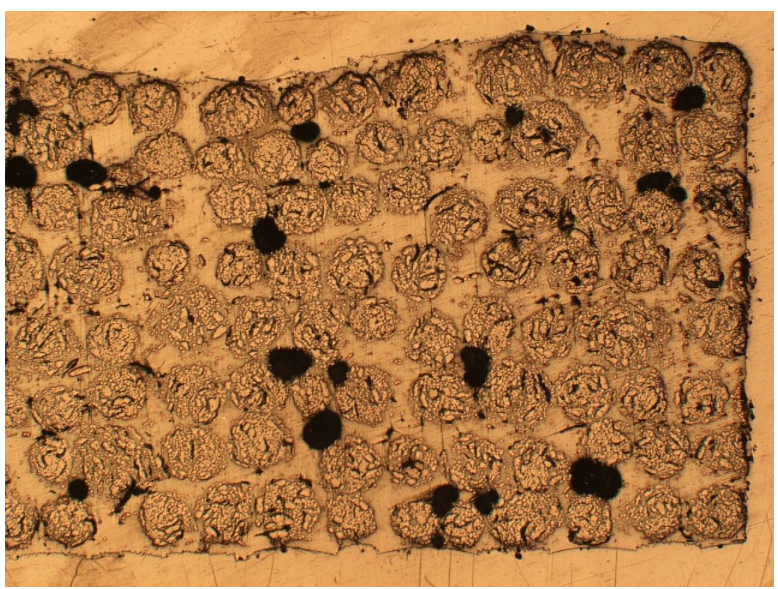

(e)

Figure 10. Microscopy images from the flax fibre panels produced from (a) B.A.M. bio epoxy; (b) Nuplex bio UP; (c) USSC bio PU; (d) Tannin; and (e) Prime 20. 
work with, and challenges the concept of an ecologically beneficial bio-based material. Finally, it can be concluded that the B.A.M. epoxy and Nuplex UP, two currently existing biobased thermoset resins, are ready to be used for industrial applications.

\subsection{Perspectives}

During this research, the interface between fibre and matrix was not under investigation and was thus not altered. However, it is well known that the use of compatibilising agents increases the mechanical properties such materials [30,31]. As described in these references, the fibre treat ment procedures are not easy to perform, and are quite time consuming. Improvements of the interface between flax fibres and bio-based thermoset resins will be a topic for further work. In addition, the infusion of bidirectional reinforcements with biobased resin will be investigated.

\section{Acknowledgements}

Prof. Schuster thanks the Centre for Advanced Composite Materials (CACM) for its kind hospitality during his sabbatical stay, enabling this piece of research described here. Financial support of the DAAD (D/10/03896) is gratefully acknowledged. The Sustainable Composites research programme at the CACM is generously supported by the Ministry for Science and Innovation, New Zealand.

\section{REFERENCES}

[1] M. Shibata and K. Nakai, "Preparation and Properties of Biocomposites Composed of Bio-Based Epoxy Resin, Tannin Acid, and Microfibrillated Cellulose,” Journal of Polymer Science: Part B: Polymer Physics, Vol. 48, No. 4, 2008, pp. 425-433. http://dx.doi.org/10.1002/polb.21903

[2] A. M. Stashevski and H. J. Deppe, "The Application of Tannine Resins as Adhesives for Wood Particle Boards,” HOLZ als Roh- und Werkstoff, Vol. 31, No. 11, 1973, pp. 417-419. http://dx.doi.org/10.1007/BF02613949

[3] C. Wang, L. Yang, B. Ni and L. Wang, “Thermal and Mechanical Properties of Cast Polyurethane Resin Based on Soybean Oil," Journal of Applied Polymer Science, Vol. 112, No. 3, 2009, pp. 1122-1127. http://dx.doi.org/10.1002/app.29537

[4] A. K. Mohanty, M. Misra and G. Hinrichsen, "Biofibres, Biodegradable Polymers and Biocomposites: An Overview,” Macromoleculare Engineering, Vol. 276, No. 3-4, 2000, pp. 1-24.

http://dx.doi.org/10.1002/(SICI)1439-2054(20000301)27 6:1<1::AID-MAME1>3.0.CO;2-W

[5] P. Pan, B. Zhu, T. Dong, S. Serizawa, M. Iji and Y. Inoue, "Kenaf Fiber/Poly(e-caprolactone) Biocomposite with Enhanced Crystallization Rate and Mechanical Properties,” Journal of Applied Polymer Science, Vol. 107, No.
6, 2008, pp. 3512-3519.

http://dx.doi.org/10.1002/app.27470

[6] M. J. John and S. Thomas, "Biofibres and Biocomposites," Carbohydrate Polymers, Vol. 71, No. 3, 2008, pp. 343364. http://dx.doi.org/10.1016/j.carbpol.2007.05.040

[7] H. Y. Cheung, K. T. Lau, Y. F. Pow, Y. Q. Zhao and D. Hui, "Biodegradation of a Silkworm Silk/PLA Composite,” Composites Part: B, Vol. 41, No. 3, 2010 pp. 223228. http://dx.doi.org/10.1016/j.compositesb.2009.09.004

[8] S. K. Majhi, S. K. Nayak, S. Mohanty and L. Unnikrishnan, "Mechanical and Fracture Behavior of Banana Fiber Reinforced Polylactic Acid Biocomposites,” International Journal Plastic Technology, Vol. 14, No. 1, 2010, pp. 5775. http://dx.doi.org/10.1007/s12588-010-0010-6

[9] A. Le Duiqou, P. Davies and C. Baley, "Analyse Ducyvle de vie d'un Biocomposite,” Matériaux \& Techniques, Vol. 98, No. 2, 2010, pp. 143-150. http://dx.doi.org/10.1051/mattech/2010021

[10] R. Moriana, F. Vilaplana, S. Karlsson and A. RibesGreus, "Improved Thermo-Mechanical Properties By The Addition of Natural Fibres in Starch Based Sustainable Biocomposites," Composites Part: A, Vol. 42, No. 1, 2011, pp. 30-40. http://dx.doi.org/10.1016/j.compositesa.2010.10.001

[11] W. Liu, L. T. Drzal, A. K. Mohanty and M. Misra, "Influence of Processing Methods and Fiber Length on Physicalproperties of Kenaf Fiber Reinforced Soy Based Biocomposites,” Composites Part: B, Vol. 38, No. 3, 2007, pp. 352-359. http://dx.doi.org/10.1016/j.compositesb.2006.05.003

[12] Z. Liu and S. Z. Erhan, “'Green’ Composites and Nanocomposites from Soybean Oil,” Material Science and Engineering A, Vol. 483-484, No. 1, 2008, pp. 708-711. http://dx.doi.org/10.1016/j.msea.2006.12.186

[13] J. Müssig, “Cotton Fibre Reinforced Thermosets versus Ramie Composites: A Comparative Study Using Petrochemical- and Agro-Based Resins,” Journal of Polymer and the Environment, Vol. 16, No. 2, 2008, pp. 94-102. http://dx.doi.org/10.1007/s10924-008-0089-4

[14] K. Adekunle, D. Åkesson and M. Skrifvars, "Biobased Composites Prepared by Compression Molding with a Novel Thermoset Resin from Soybean Oil and a NaturalFiber Reinforcement," Journal of Applied Polymer Sciences, Vol. 116, No. 3, 2010, pp. 1759-1765.

[15] J. T. Kim and A. N. Netravali, "Mechanical and Thermal Properties of Sisal Fiber-Reinforced Green Composites with Soy Protein/Gelatin Resins," Journal of Biobased Materials and Bioenergy, Vol. 4, No. 4, 2010, pp. 338345. http://dx.doi.org/10.1166/jbmb.2010.1098

[16] G. Mehta, A. K. Mohanty, K. Thayer, M. Misra and L. T. Drzal, "Novel Biocomposites Sheet Molding Compounds for Low Cost Housing Panel Applications," Journal of Polymer and the Environment, Vol.13, No. 2, 2005, pp. 169-175. http://dx.doi.org/10.1007/s10924-005-3211-x

[17] M. A. Dweib, B. Hu, H. W. Shenton III and R. P. Wool, "Bio-Based Composite Roof Structure: Manufacturing and Processing Issues,” Composite Structures, Vol. 74, 
No. 4, 2006, pp. 379-388.

http://dx.doi.org/10.1016/j.compstruct.2005.04.018

[18] J. Müssig, "Karosserie aus Naturfasern und Pflanzenöl," Kunststoffe, Vol. 97, No. 3, 2007, pp. 78-83.

[19] K. Satyanarayana and F. Wypych, "Characterization of Natural Fibers,” In: S. Fakirov and D. Bhattacharrya, Eds., Handbook of Engineering Biopolymers: Homopolymers, Blends and Composites, Hanser Gardner Publications, 2007, p. 34.

[20] T. Reußmann, "Entwicklung eines Verfahrens zur Herstellung von Langfasergranulat mit Naturfaserverstärkung,” Ph.D. Dissertation, Technische Universität Chemnitz, Chemnitz, 2003, p. 22.

[21] S. Chabba, G. F. Matthews and A. N. Netravali, “'Green Composites Using Cross-Linked Soy Flour and Flax Yarns,” Green Chemistry, Vol. 7, No. 8, 2005, pp. 576581. http://dx.doi.org/10.1039/b410817e

[22] S. Alix, S. Marais, C. Morvan and L. Lebrun, "Biocomposite Materials Fromflax Plants: Preparation and Properties,” Composites Part: A, Vol. 39, No. 12, 2008, pp. 1793-1801. http://dx.doi.org/10.1016/j.compositesa.2008.08.008

[23] M. A. Dweib, B. Hu, A. O’Donnell, H. W. Shenton and R. P. Wool, "All Natural Composite Sandwich Beams for Structural Applications,” Composite Structures, Vol. 63, No. 2, 2004, pp. 147-157. http://dx.doi.org/10.1016/S0263-8223(03)00143-0

[24] J. Schuster, M. Duhovic and D. Bhattacharyya, "Manufacturing and Processing of Polymer Composite Materials,” In: S. Fakirov and D. Bhattacharrya, Eds., Synthetic Polymer-Polymer Composites, Hanser Gardner Publications, 2012, pp. 18-24. http://dx.doi.org/10.3139/9781569905258.001

[25] Q. Govignon, S. Bickerton, J. Morris and P.A. Kelly, "Full Field Monitoring of the Resin Flow and Laminate
Properties during the Infusion Process," Composites Part: A, Vol. 39, No. 9, 2008, pp. 1412-1426. http://dx.doi.org/10.1016/j.compositesa.2008.05.005

[26] P. Simacek, D. Heider, J. W. Gillespie Jr. and S. Advani, "Post-Filling Flow in Vacuum Assisted Resin Transfer Molding Processes: Theoretical Analysis,” Composite Part: A, Vol. 40, No. 6-7, 2009, pp. 913-924. http://dx.doi.org/10.1016/j.compositesa.2009.04.018

[27] S. Mekic, C. A. Ulven, I. S. Akhatov, E. Jerke and E. Kerr-Anderson, "Evaluation of In-Plane and Transverse Permeability of Flax Preformsfor Biocomposite Materials," Journal of Biobased Materials and Bioenergy, Vol. 3, No. 2, 2009, pp. 156-164. http://dx.doi.org/10.1166/jbmb.2009.1020

[28] K. Van de Velde and E. Baetens, "Thermal and Mechanical Properties of Flax Fibres as Potential Composite Reinforcements," Macromoleculare Materials and Engineering, Vol. 286, No. 6, 2001, pp. 342-349. http://dx.doi.org/10.1002/1439-2054(20010601)286:6<34 2::AID-MAME342>3.0.CO;2-P

[29] B. Lauke, W. Beckert and K. Schneider, "Interlaminar Shear Strength Evaluation of Curved Composite Samples,” Applied Composite Materials, Vol. 1, No. 1, 1994 pp. 267-271. http://dx.doi.org/10.1007/BF00568283

[30] Q. Lui, T. Stuart, M. Hughes, H. H. Sharma and G. Lyons, "Structural Biocomposites from Flax-Part II: The Use of PEG and PVA as Interfacial Compatibilising Agents," Composites: Part A, Vol. 38, No. 5, 2007, pp. 1403-1413. http://dx.doi.org/10.1016/j.compositesa.2006.08.009

[31] J. Gassan, T. Dietz and A. Bledzki, "Effect of Silicone Interphase on the Mechanical Properties of Flax-Polyurethane Composites," Composites Interfaces, Vol. 2, No. 7, 2000, pp. 103-115. http://dx.doi.org/10.1163/156855400300184262 